follow-up period, the study of brain structure and function cited $^{2}$ was not based on a community sample. Their findings were derived from a cohort of acutely ill hospitalised adolescents, and were most evident in those who remained at low weight in their 20 s.

I am grateful to learn about the Junior MARSIPAN report, and hope that most readers recognised that I was situating my response to Robinson's article from a community perspective, including how 'risk' may be constructed by those responding to newly presenting patients with anorexia.

1 Wentz E, Gillberg IC, Anckarsäter H, Gillberd C, Råstam M. Adolescentonset anorexia nervosa: 18-year outcome. Br J Psychiatry 2009; 194: 168-74.

2 Chui HT, Christensen BK, Zipursky RB, Richards BA, Hanratty MK, Kabani NJ, et al. Cognitive function and brain structure in females with a history of adolescent-onset anorexia nervosa. Pediatrics 2008; 122 e426-37.

Robert M. Wrate MDBS DPM FRCPsych, psychiatrist, NHS Shetland, Edinburgh, UK, email: robertwrate123@btinternet.com

doi: 10.1192/pb.36.11.437a

\section{Mental health awareness can learn from the promotion of the Paralympics}

It is clear from the Olympic-themed articles in the August 2012 issue of The Psychiatrist that we are all agreed on one thing: sport is good. 'Whether this be in the context of promoting physical activity in the general population as part of an Olympic legacy pledge, or as a means of battling the social exclusion that many people with mental illness experience. We are currently riding on the crest of an Olympic-induced wave. But what has impressed me most is the way in which the Paralympic Games have been promoted. From the 'Meet the Superhumans' slogan of the Channel 4 advertising campaign, the message from the outset has been one of personal strength, resilience and determination, and ultimately, triumph through adversity. We have heard stories of athletes who have endured great personal tragedy, but have managed to turn their experience into success. The positive way in which such awe-inspiring individuals have been presented has captured the public's imagination. This should serve as a beacon of hope to mental health professionals who are determined to challenge the stigma which our service users experience. After all, do they not have equally inspirational stories of human spirit in the face of mental illness and disability? It is our duty to find equally effective ways of presenting their life stories in such a positive light, with the hope that this will help in the battle against mental health stigma.

1 Currie A. The London 2012 Olympics - will there be a legacy for mental health? Psychiatrist 2012; 36: 281-3.

Aashish Tagore, Specialist Registrar, Mersey Deanery, UK, email: aashish.tagore@nhs.net

doi: $10.1192 / \mathrm{pb} .36 .11 .438$

\section{Spirituality and psychiatric patients}

Having studied both the Book of Job and the Bhagavad Gita, I find it difficult to agree with John Price that either Job or Arjuna 'suffered from depression'.
These mythical, rather than historical, characters were temporarily unhappy, yes; even miserable; but by no means hopeless, helpless or worthless. They were not described as experiencing diurnal mood variation, sleep or appetite disturbance, or reduced concentration. In terms of emotion, a healthy degree of awe and wonder can be deduced, particularly in the case of Arjuna. It is equally unwise, in my view, to read as much into the text as to say that Arjuna 'had a typical panic attack'. There is very little that is typical about either Job or Arjuna!

Nevertheless, although I take issue with Dr Price on questions about diagnosis, I do consider valid and valuable his observation that 'those treating depressed agnostics should look for a secular equivalent to joyous total surrender to God'.

For a number of years I acted as an independent medical examiner for insurance companies, and assessed dozens of people claiming income protection insurance through being unable to work on the grounds of psychiatric illness and disability. Often, feeling undervalued and exploited in an occupation which was central to their sense of identity, they were now (with few exceptions) without any vital sense of purpose; beaten, angry, resentful and bewildered, sure only that they could not go back into the workplace to risk further humiliation and insult. Many avoided human society altogether, with symptoms of anxiety, depression, panic attacks while away from home, agoraphobia and social phobia. They also avoided psychiatric services, and therefore help, deeming it further humiliation to be considered mentally ill.

Men and women were more or less equally represented, and it was also striking that not one expressed any religious belief or connection, or undertook any kind of even secular spiritual practice on a regular or frequent basis.

I believe that human experience needs interpreting according to five seamlessly connected dimensions: physical, biological, psychological, social and spiritual. I further believe in routinely including the spiritual dimension when assessing psychiatric patients. John Price seems to be pointing in a similar direction.

Spirituality and religion are linked, but can be distinguished and detached from one another. People tend to take relatively fixed positions on both and concerning the relationship between them, but the distinctions are subtle. It can often boil down to a question of language, rather than substance. The words 'God', 'religion' and 'spirituality', for example, have very different meanings for different people. A person's spirituality concerns whatever is most meaningful to them, at the deepest level, whether couched in terms that are religious or secular. If there is a void, then that too is part often a key part - of the presenting problem. Such a void first needs detecting and then healing. In this, even if it does not reach the magnitude of Price's 'joyous total surrender', some kind of improved degree of acceptance in the face of adversity and loss is frequently the first and most decisive step.

1 Price JS. Lessons from sacred texts. Psychiatrist 2012; 36: 357

Larry Culliford, retired psychiatrist and author, West Sussex, UK, email: auud26@dsl.pipex.com

doi: 10.1192/pb.36.11.438a 